\title{
Prolonged Coagulopathy, Ecchymoses, and Microangiopathic Hemolytic Anemia Following Hump-Nosed Pit Viper (Hypnale bypnale) Bite in Sri Lanka
}

Rathnayaka Mudiyanselage M.K. Namal Rathnayaka, MBBS, MA, MSc in Medical Tox., Dip. in Tox. Dip. in OH\&S.; Senanayake A.M. Kularatne, MBBS, MD, MRCP (UK), FRCP (Lond); Anusha Nishanthi Ranathunga, MBBS; Mahinda Kumarasinghe, MBBS, MD; Jayantha Rajapakse, BVSc, PhD; Shirani Ranasinghe, BVSc, MPhil, PhD

From the Department of Veterinary Pathobiology, Faculty of Veterinary Medicine and Animal Science, University of Peradeniya, Sri Lanka (Drs Rathnayaka and Rajapakse); the Faculty of Medicine, University of Peradeniya, Sri Lanka (Drs Kularatne and Ranasinghe); the Medical Unit, Provincial General Hospital, Ratnapura, Sri Lanka (Drs Ranathunga and Kumarasinghe); and the Intensive Care Unit, Provincial General Hospital, Ratnapura, Sri Lanka (Dr Rathnayaka).

A 74-year-old previously healthy woman was bitten by a hump-nosed pit viper (Hypnale hypnale) at dusk causing incoagulable blood lasting for 6 days. Further, she developed ecchymoses over her forearms, upper arms, hands, and lower back on day 4 after the snakebite, and microangiopathic hemolytic anemia (MAHA). Features of this nature are rare after hump-nosed pit viper bite.

Keywords: snakebites, hump-nosed pit viper, Hypnale hypnale, ecchymoses, coagulopathy, microangiopathic hemolysis

\section{Introduction}

Hump-nosed pit vipers of the genus Hypnale are the most common cause of all snakebites in Sri Lanka, ${ }^{1}$ causing 22 to $77 \%$ of all snakebites. ${ }^{2,3}$ There are 3 species of genus Hypnale. $H$. hypnale, $H$. zara, and $H$. nepa have been identified in Sri Lanka, ${ }^{4}$ and, of them, the latter 2 are endemic to the island. $H$. hypnale is also found in the Western Ghats of India. The manifestations of local envenoming, such as pain, swelling, hemorrhagic blistering, and necrosis after hump-nosed pit viper bites are well described in the literature. ${ }^{5-8}$ Moreover, systemic manifestations such as coagulopathy, acute kidney injury, chronic kidney disease, ${ }^{6,9-13}$ thrombotic microangiopathy, ${ }^{13}$ ischemic stroke, ${ }^{14}$ inferior myocardial infarction, atrial fibrillation, and cardiac arrest ${ }^{15}$ have been described, which qualified it as a highly venomous snake. Extensive literature searches on the effects of envenoming by hump-nosed vipers did not find situations of appearance of ecchymotic patches

Corresponding author: Rathnayaka Mudiyanselage M.K. Namal Rathnayaka, MBBS, MA, MSc in Medical Tox., Dip. in Tox. Dip. in OH\&S., University of Peradeniya, Department of Veterinary Pathobiology. Intensive Care Unit-Provincial General Hospital, No. 181, Flower Road, New Town Housing Scheme 01, New Town, Ratnapura, Sri Lanka; e-mail: namalrath@yahoo.com.

Submitted for publication January 2017.

Accepted for publication May 2017. similar to this case described from the wet zone of Sri Lanka.

\section{Case Report}

A 74-year-old previously healthy woman with a history of snakebite was transferred from a primary hospital to the Provincial General Hospital, Ratnapura (PGHR) for further management. The formalin-preserved offending snake specimen was sent along with the patient. The history goes 3 days back when she was bitten by a snake on her right foot at about 1900 hours in her home garden. Without any delay, she was admitted to the nearest primary hospital where the offending snake was identified as hump-nosed pit viper by the attending medical officer. She was in severe pain and had developed swelling at the bitten site with bleeding from the fang puncture. The 20-minute whole blood clotting test (WBCT20) was positive, and she continued to bleed from the venipuncture sites. She was kept at the primary hospital for 3 days, and on day 4, as she developed ecchymotic patches on both forearms, upper arms, hands, and the lower back, she was transferred to the PGHR. She was not taking any long-term medication, including herbal medicines. There was no past or family history of abnormal bleeding tendency. 


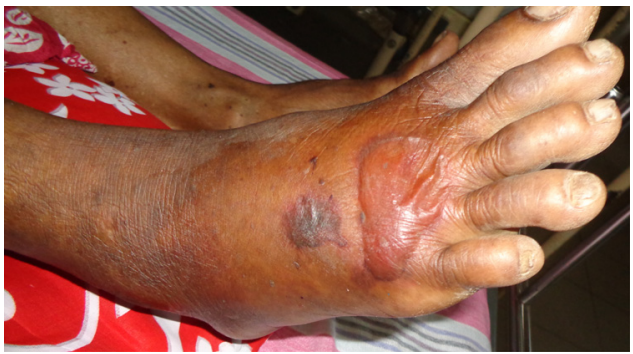

Figure 1. Necrosis, swelling, and blistering at the site of bite on the right foot on day 4 after snakebite.

On admission to the PGHR, the patient had necrosis, moderate swelling, and blistering over the right foot (Figure 1).

There was bleeding from venipuncture sites but the patient had normal-colored urine. Her blood pressure
(BP) was $130 / 80 \mathrm{~mm} \mathrm{Hg}$ and her pulse rate was 80 beats/min. Respiratory rate was 15 breaths $/ \mathrm{min}$ and examination of the respiratory system, nervous system, and abdomen revealed no abnormality. Patches of ecchymoses were observed on both forearms, upper arms, hands, and left lower back side (Figure 2).

Investigations were as follows (Table). Urine full report and electrocardiogram (ECG) were normal. The WBCT20 on admission and subsequent readings of 6 hourly intervals remained nonclotting for 48 hours (altogether, 6 days). Blood picture done on admission (day 4 after snakebite) showed normochromic normocytic red cells, many polychromatics, acanthocytes, and a few fragmented red blood cells (schistocytes) suggestive of microangiopathic hemolytic anemia (MAHA) (Figure 3).

She was treated with intravenous administration of 3 packs of fresh frozen plasma (FFP) daily for first 2 days.
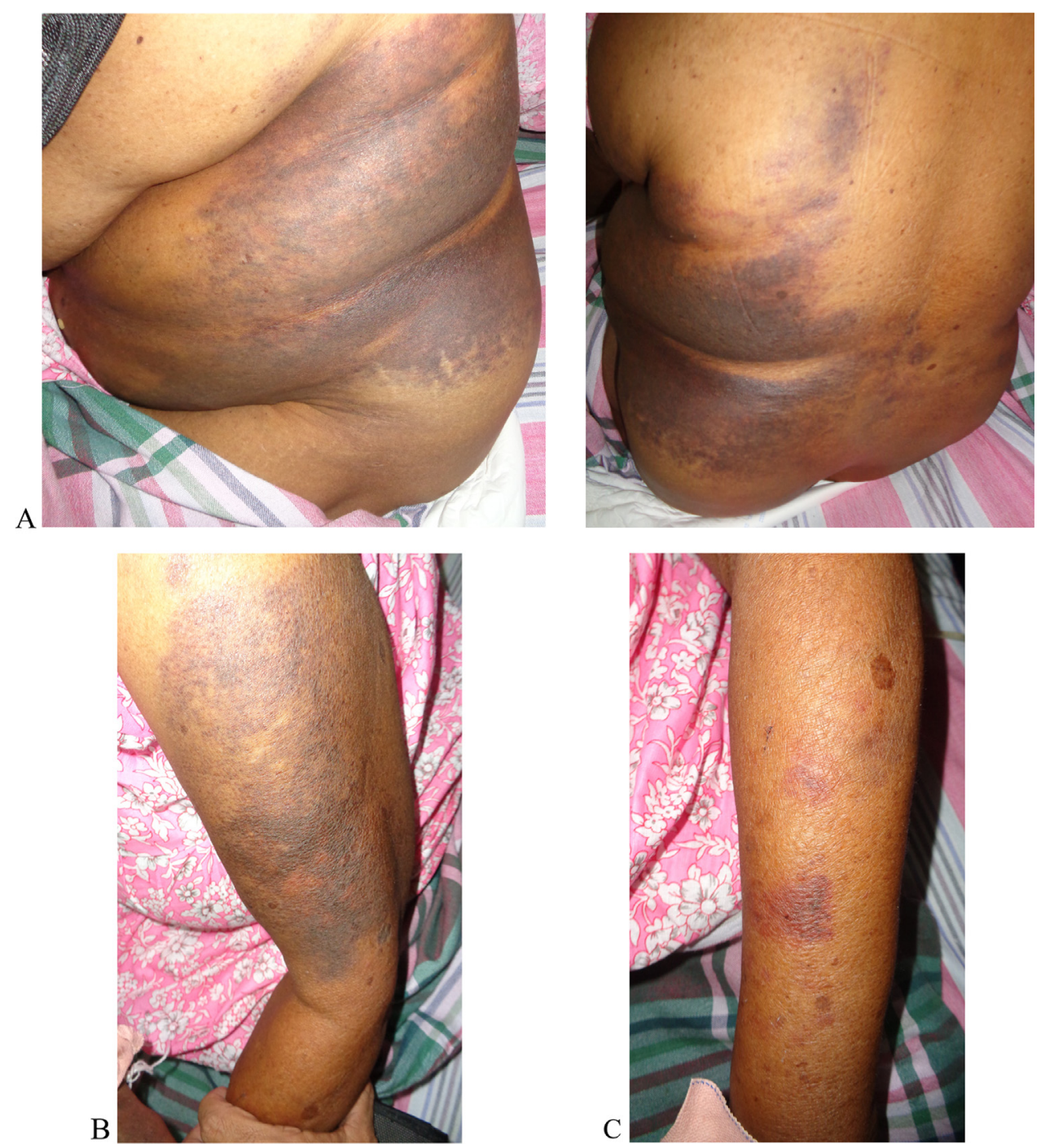

Figure 2. Ecchymoses on day 4 after snakebite on A, left lower back side; B, left upper arm; and C, left forearm. 
Table. Investigation findings; note that renal biochemistry was normal throughout

\begin{tabular}{|c|c|c|c|c|}
\hline Investigation & Day 4 (on admission to PGHR) & Day 5 & Day 6 & Day 7 \\
\hline $\mathrm{WBC}\left(\mathrm{x} 10^{3} / \mu \mathrm{L}\right)$ & 4.5 & 7.2 & 6.3 & 6.4 \\
\hline Neutrophils (\%) & 55.4 & 76 & 60.5 & 60 \\
\hline Lymphocytes (\%) & 35.6 & 17.9 & 28.9 & 39 \\
\hline Platelets $\left(\times 10^{3} / \mu \mathrm{L}\right)$ & 193 & 170 & 168 & 158 \\
\hline Hematocrit (PCV) (\%) & 22.4 & 24.1 & 23.7 & 30.3 \\
\hline $\mathrm{Hb}(\mathrm{g} / \mathrm{dL})$ & 7.7 & 7.9 & 7.8 & 10.2 \\
\hline MCV (normal 80-95.5 fL) & 92.7 & 94.3 & 93.3 & 94.4 \\
\hline MCH (normal 27-31 pg) & 32 & 31 & 30.6 & 31.8 \\
\hline MCHC (normal 33-37 g/dL) & 34.5 & 32.9 & 32.8 & 33.7 \\
\hline Serum creatinine $(\mu \mathrm{mol} / \mathrm{L})$ & 68 & Not done & 90.3 & 88.7 \\
\hline Blood urea $(\mathrm{mmol} / \mathrm{L})$ & 2.9 & Not done & 4.9 & Not done \\
\hline $\mathrm{Na}^{+}(\mathrm{mmol} / \mathrm{L})$ & 137 & Not done & 144 & 141 \\
\hline $\mathrm{K}^{+}(\mathrm{mmol} / \mathrm{L})$ & 4.1 & Not done & 3.2 & 3.6 \\
\hline PT (seconds) & 34 & 23 & 13.8 & 15.7 \\
\hline INR & 2.92 & 1.91 & 1.15 & 1.27 \\
\hline APTT (seconds) & $40 / 25$ & $32 / 25$ & $22 / 25$ & $22.7 / 25$ \\
\hline SGOT/AST (U/I) & 45 & Not done & 55.5 & Not done \\
\hline SGPT/ALT (U/I) & 51 & Not done & 53.2 & Not done \\
\hline Bleeding time (normal 2-8 minutes) & & 6.5 minutes & & \\
\hline Clotting time (normal 2-10 minutes) & & $>10$ minutes & & \\
\hline $\mathrm{CRP}(\mathrm{mg} / \mathrm{L})$ & 20 & & & \\
\hline
\end{tabular}

WBC, white blood cell; PCV, packed cell volume; Hb, hemoglobin; MCV, mean corpuscular volume; $\mathrm{MCH}$, mean corpuscular hemoglobin; MCHC, mean corpuscular hemoglobin concentration; PT, prothrombin time; INR, international normalized ratio; APTT, activated partial thromboplastin time; SGOT, serum glutamic oxaloacetic transaminase; AST, aspartate aminotransferase; SGPT, serum glutamic-pyruvic transaminase; ALT, alanine aminotransferase; CRP, C-reactive protein.

Spreading of ecchymoses was observed from the left lower back to the right lower back on day 5 after snakebite (Figure 4). One pack of blood transfusion was done on day 6 after snakebite as hemoglobin $(\mathrm{Hb})$ was low $(7.8 \mathrm{~g} / \mathrm{dL})$. However, WBCT20 became normal (less than 20 minutes) on day 3 (snakebite day 6) onwards, and clotting profile became normal (Table). She maintained normal urine output and was discharged on day 4 of hospital admission (day 8 after snakebite) with arranged clinic follow-up. The necrosis of the site of bite did not extend to deep tissues, and it was only in superficial tissues of the dorsum of the foot. It was partially resolved when the patient was discharged on having cleaning and dressing daily. Her ecchymotic patches completely disappeared 2 months after the snakebite. Applying the key described by Maduwage
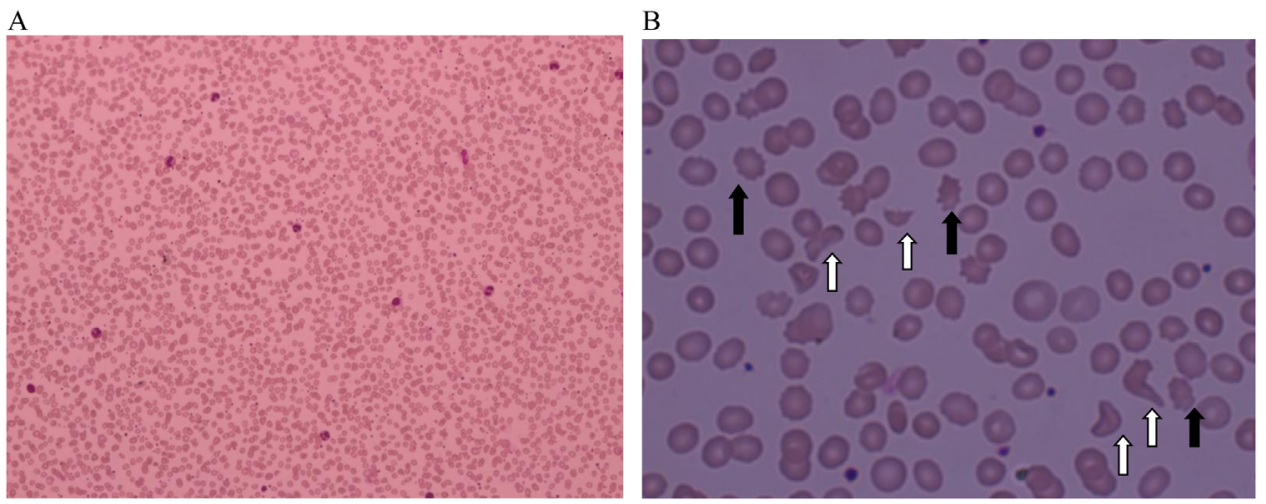
Figure 3. Microangiopathic hemolytic anemia (MAHA) found in day 4 after snakebite A, x 20, B, x $100 \widehat{P}$ acanthocytes
blood cells (schistocytes). 

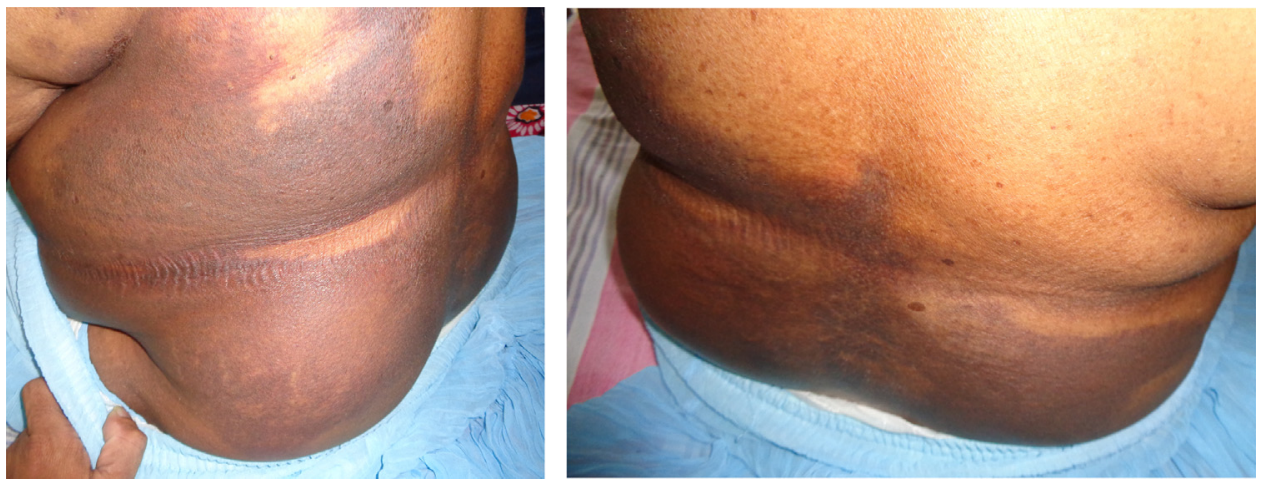

Figure 4. Spreading of ecchymoses into the right side of back on day 5 after snakebite.

et al 2009, the offending species of hump-nosed pit viper in this index case was identified as $H$. hypnale (Figure 5).

\section{Discussion}

We report a case of MAHA with multiple ecchymoses in an elderly patient after $H$. hypnale envenoming. The bite happened at dusk and first led to incoagulability of blood persisting over days, development of ecchymotic patches on day 4 after bite, and subsequent detection of significant drop of $\mathrm{Hb}$ due to MAHA. She was
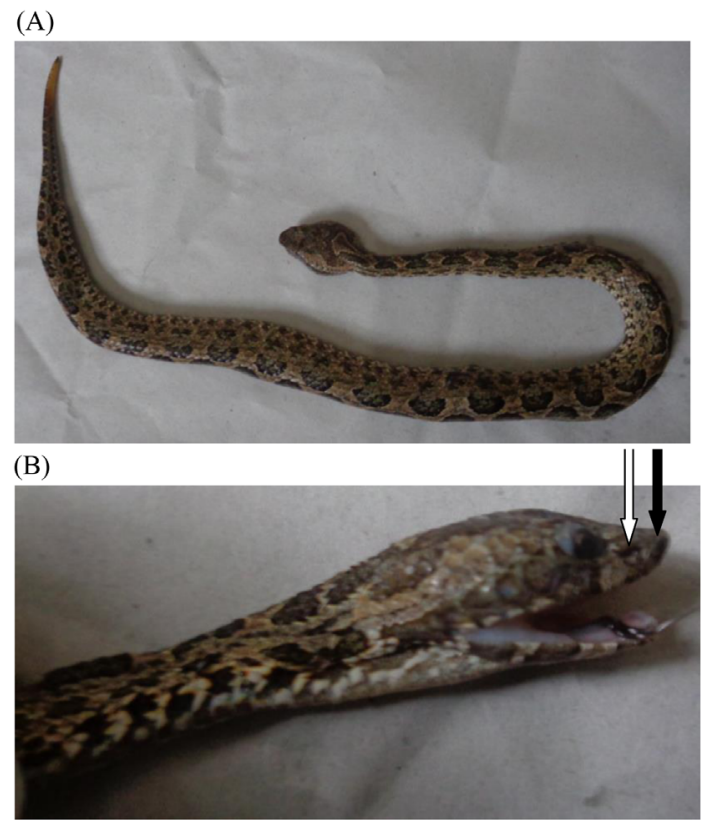

Figure 5. A, Offending snake-H. hypnale (hump-nosed pit viper), female snake $400 \mathrm{~mm}$ in total length. B, Note that the snout tip (hump indicated in black arrow) is not raised (vs a wart-like protuberance at the tip of the snout in H. zara and H. nepa), and has keeled costal scales (versus smooth in $H$. nepa). White arrow is indicated the pit organ (loreal pit), which is a characteristic feature of pit vipers, is inbetween the eye and the nostril. transfused with blood products (FFP and blood) and she made a complete recovery following the snakebite. The pathophysiology of MAHA is due to the damage of the endothelial layer of small blood vessels with resulting fibrin deposition and platelet aggregation. A fibrin mesh is formed in a snakebite because of the increased activation of the coagulation system due to the snake venom. ${ }^{16}$ As red blood cells travel through these damaged vessels, they are fragmented resulting in intravascular hemolysis causing hemolytic anemia. These fragmented red cells are seen in light microscopy of peripheral blood films as schistocytes and helmet cells (Figure 3). It was a good fortune that our patient had normal renal functions and platelet count as the extreme end of this cascade would have been thrombotic microangiopathy (TMA), which is characterized by combination of MAHA, acute kidney injury, and thrombocytopenia. ${ }^{13}$ Onset of these types of complications would have been averted with the use of specific antivenom against hump-nosed viper venom, which remains a future challenge in Sri Lanka. A new polyspecific antivenom against the venom of Daboia russelii, Echis carinatus, Hypnale hypnale, and Naja naja is in the trial stage in Sri Lanka, and it was successful for more venoms than Indian antivenoms. ${ }^{17}$ However, this antivenom was not available at PGHR, as it is in the clinical trail stage in select hospitals in Sri Lanka.

Concealed coagulopathy detected by WBCT20 is an uncommon systemic manifestation following humpnosed pit viper bite. ${ }^{6,9,12}$ Of the 3 species of humpnosed vipers, $H$. hypnale ${ }^{6}$ and $H$. $z_{a r a}{ }^{18}$ cause coagulopathy, whereas such effect has not yet been published in $H$. nepa bites probably due to its limited distribution of the snake in Sri Lanka and its infrequency of bites. Coagulopathy is the most common systemic complication of $H$. hypnale bites, with incidence ranging from $4.3^{8}$ to $39 \%{ }^{6}$ of cases. In the past, different terms had been used to denote pathophysiology of coagulopathy 
in snake envenoming, such as disseminated intravascular coagulation (DIC), defibrination syndrome, and procoagulant coagulopathy. ${ }^{19}$ Recently, the term venom-induced consumption coagulopathy (VICC) has been proposed as it covers a larger spectrum of coagulopathy specific to envenoming. ${ }^{20}$ It is said that VICC results from the activation of the clotting pathway by procoagulant toxins in snake venom that act at different levels of the clotting pathway, and these toxins are named as factor $\mathrm{V}$ activators, factor $\mathrm{X}$ activators, prothrombin activators, and thrombinlike enzymes (TLEs). ${ }^{21}$ From these, $H$. hypnale venom contains several hemotoxins, such as TLEs, snake venom metalloproteinases (SVMPs), and C-type lectins. ${ }^{22}$ The diagnosis and monitoring of VICC requires coagulation studies and clotting times. ${ }^{23}$ However, due to limited access to these clotting tests, the most frequently used simple bedside clotting test is the WBCT20, to detect coagulopathy early. ${ }^{24,25}$

Overt bleeding manifestations following hump-nosed pit viper bite are rare, but there are published reports that described such manifestations: bleeding from venipuncture sites, ${ }^{26}$ overt gastrointestinal bleeding, ${ }^{27}$ oozing of blood from the site of bite, ${ }^{9}$ local bleeding at bitten site, ${ }^{6,8}$ spontaneous systemic hemorrhages (gum bleeding, hematuria, hematemesis), ${ }^{6}$ and retroperitoneal hemorrhage. ${ }^{28}$ However, bleeding into subcutaneous tissues (ecchymoses) following genus Hypnale envenoming has not been described as in this case scenario.

Ecchymosis is a subcutaneous spot of bleeding with diameter larger than 1 centimeter, whereas petechiae are small, red or purple hemorrhagic spots that are approximately 1 to $2 \mathrm{~mm}$ in size. Purpura are larger than the petechiae, but less than $1 \mathrm{~cm}$ in size. Both purpura and ecchymoses may be irregular in shape, depending upon the amount of pooled blood. Our patient had normal bleeding time and normal platelet count, which together may exclude defective platelets function and thrombocytopenia, respectively, to contribute for gross skin bleeding. However, vascular fragility cannot be excluded, as some snake venom has vascular factors. So generalized ecchymoses in this patient could be due to the deficient clotting factors, as coagulopathy was corrected on day 6 either spontaneously or with the administration of FFP or, by that time, venom could be eliminated from the plasma, because the pharmacokinetics of $H$. hypnale venom shows a rapid and a slow distribution phase followed by a long elimination phase with a systemic clearance of $6.8 \mathrm{~mL} / \mathrm{h} / \mathrm{kg}$ in intravenous or intramuscular route in rabbits. ${ }^{29}$ There is evidence to support the benefit of FFP in bleeding patients due to VICC with a broad range of factor deficiencies because of procoagulant toxins. ${ }^{30-32}$ As FFP contains almost all the factors-such as fibrinogen, factor V, factor VIII, and factor $\mathrm{X}$-treatment with FFP would restore the clotting cascade. On the other hand, transfusion of FFP in patients with snake envenoming may be harmful because there were fatalities of FFP therapy. ${ }^{30,33}$ Therefore, the current practice is giving FFP for patients with snakebites when there is coagulopathy associated with clinically significant active bleeding manifestations or a notable risk thereof even after having antivenom therapy. In this patient, VICC might spontaneously be corrected, but we administered FFP due to the unavailability of specific antivenom for $H$. hypnale venom and the ecchymoses gradually spreading. This case would expand the spectrum of bleeding tendency following hump-nosed pit viper bites and MAHA as a clinical manifestation.

Acknowledgments: We thank the staff of medical wards and Dr. Radha Jayathunga, Consultant Hematologist, Provincial General Hospital, Ratnapura-Sri Lanka and the relatives of the patient.

Author Contributions: Literature search (RMMKNR, ANR); patient's management (MK, RMMKNR, ANR); drafted the first manuscript and wrote the case histories (RMMKNR, SAMK, ANR, JR, SR); read and approved the final manuscript (RMMKNR, SAMK, ANR, MK, JR, SR).

Financial/Material Support: None.

Disclosures: None.

Consent: Written consent for publication of this case history and photographs was obtained from the patient.

\section{References}

1. Kasturiratne A, Pathmeswaran A, Fonseka MM, Lalloo DC, Brooker S, de Silva HJ. Estimates of disease burden due to land-snake bite in Sri Lankan hospitals. Southeast Asian J Trop Med Public Health. 2005;36:733-740.

2. De Silva A. Snake bites in Anuradhapura district. The Snake. 1981;13:117-130.

3. Kasturiratne A, Wickremasinghe AR, de Silva N, et al. The global burden of snakebite: a literature analysis and modelling based on regional estimates of envenoming and deaths. PLoS Med. 2008;5:e218.

4. Maduwage K, Silva A, Manamendra-Arachchi K, Pethiyagoda RA. A taxonomic revision of the South Asian hump-nosed pit vipers (Squamata: Viperidae: Hypnale). Zootaxia. 2009;2232:1-28.

5. Sellahewa KH, Kumararatne MP. Envenomation by the hump-nosed viper (Hypnale hypnale). Am J Trop Med Hyg. 1994;51:823-825.

6. Ariaratnam CA, Thuraisingam V, Kularatne SA, et al. Frequent and potentially fatal envenoming by hump-nosed pit vipers (Hypnale hypnale and H. nepa) in Sri Lanka: lack of effective antivenom. Trans $R$ Soc Trop Med Hyg. 2008;102:1120-1126.

7. Wijewantha HS, Sellahewa KH. Hump nosed viper bite in Sri Lanka-descriptive observational study of 1543 cases. Asian Pac J Trop Med. 2010;3:902-905. 
8. Maduwage K, Isbister GK, Silva A, Bowatta S, Mendis S, Gawarammana I. Epidemiology and clinical effects of hump-nosed pit viper (Genus: Hypnale) envenoming in Sri Lanka. Toxicon. 2013;61:11-15.

9. Premawardena AP, Seneviratne SL, Gunatilake SB, de Silva HJ. Excessive fibrinolysis: the coagulopathy following Merrem's hump-nosed viper (Hypnale hypnale) bites. Am J Trop Med Hyg. 1998;58:821-823.

10. Namal Rathnayaka RMMK, Ranathunga PEAN. Acute kidney injury which leads to chronic kidney disease and death following hump nosed pit viper (Genus: Hypnale) envenoming. J Ratnapura Clin Soc. 2016;11:40-42.

11. Kularatne SA, Ratnatunga N. Severe systemic effects of Merrem's hump-nosed viper bite. Ceylon Med J. 1999;44: 169-170.

12. Joseph JK, Simpson ID, Menon NCS, et al. First authenticated cases of life-threatening envenoming by the hump-nosed pit viper (Hypnale hypnale) in India. Trans $R$ Soc Trop Med Hyg. 2007;101:85-90.

13. Herath N, Wazil A, Kularatne S, et al. Thrombotic microangiopathy and acute kidney injury in hump-nosed viper (Hypnale species) envenoming: a descriptive study in Sri Lanka. Toxicon. 2012;60:61-65.

14. Jeevagan V, Chang T, Gnanathasan CA. Acute ischemic stroke following Hump-nosed viper envenoming; first authenticated case. Thromb J. 2012;10:21.

15. Thillainathan S, Priyangika D, Marasinghe I, Kanapathippillai K, Premawansa G. Rare cardiac sequelae of a humpnosed viper bite. BMC Res Notes. 2015;8:437.

16. Than-Than, Francis N, Tin-Nu-Swe, et al. Contribution of focal haemorrhage and microvascular fibrin deposition to fatal envenoming by Russell's viper (Vipera russelli siamensis) in Burma. Acta Trop. 1989;46:23-38.

17. Villalta M, Sánchez A, Herrera M, et al. Development of a new polyspecific antivenom for snakebite envenoming in Sri Lanka: analysis of its preclinical efficacy as compared to a currently available antivenom. Toxicon. 2016;122:152-159.

18. Maduwage K, Kularatne K, Wazil A, Gawarammana I. Coagulopthy, acute kidney injury and death following Hypnale zara envenoming: the first case report from Sri Lanka. Toxicon. 2011;58:641-643.

19. Isbister GK, Scorgie FE, O'Leary MA, et al. Factor deficiencies in venom-induced consumption coagulopathy resulting from Australian elapid envenomation: Australian Snakebite Project (ASP-10). J Thromb Haemost. 2012;8:2504-2513.

20. Isbister GK. Procoagulant snake toxins: laboratory studies, diagnosis and understanding snake bite coagulopathy. Semin Throm Hemost. 2009;35:93-103.
21. Lu Q, Clemetson JM, Clemetson KJ. Snake venoms and hemostasis. J Thromb Haemost. 2005;3:1791-1799.

22. Tan CH, Tan NH, Sim SM, Fung SY, Gnanathasan CA. Proteomic investigation of Sri Lankan hump-nosed pit viper (Hypnale hypnale) venom. Toxicon. 2015;93:164-170.

23. Isbister GK, Duffull SB, Brown SG, ASP Investigators, Failure of antivenom to improve recovery in Australian snakebite coagulopathy. QJM. 2009;102:563-568.

24. Warrell DA, Davidson NMcD, Greenwood BM, et al. Poisoning by bites of the saw-scaled or carpet viper (Echis carinatus) in Nigeria. Q J Med. 1977;46:33-62.

25. Kularatne SA, Budagoda BD, Gawarammana IB, Kularatne WK. Epidemiology, clinical profile and management issues of cobra (Naja naja) bites in Sri Lanka: first authenticated case series. Trans R Soc Trop Med Hyg. 2009;103:924-930.

26. Dharmaratne L, Gunawardena U. Generalised bleeding tendency and acute renal failure following Merrem's hump-nosed viper bite. J Ceylon Coll Physic. 1989: 21-22.

27. de Silva A, Wijekoon ASB, Jayasena L, et al. Haemostatic dysfunction and acute renal failure following envenoming by Merrem's hump-nosed viper (Hypnale hypnale) in Sri Lanka: first authenticated case. Trans $R$ Soc Trop Med Hyg. 1994;88:209-212.

28. Sunanda H, Tilakaratne S, Coomaraswamy W. Retroperitoneal haemorrhage following a hump-nosed viper (Hypnale hypnale) bite; a late presentation. Galle Med J. 2010;15:41-42.

29. Tan CH, Sim SM, Gnanathasan CA, Fung SY, Tan NH. Pharmacokinetics of the Sri Lankan hump-nosed pit viper (Hypnale hypnale) venom following intravenous and intramuscular injections of the venom into rabbits. Toxicon. 2014;79:37-44.

30. Isbister GK, Buckley NA, Page CB, et al. A randomized controlled trial of fresh frozen plasma for treating venominduced consumption coagulopathy in cases of Australian snakebite (ASP-18). J Thromb Haemost. 2013;11:13101318.

31. Sellahewa KH. Can fresh frozen plasma prevent acute kidney injury after hump-nosed viper bite? Open J Nephrol. 2013;3:70-74.

32. Maduwage K, Isbister GK. Current treatment for venominduced consumption coagulopathy resulting from snakebite. PLoS Negl Trop Dis. 2014;8:e3220.

33. Isbister GK, Jayamanne S, Mohamed F, et al. A randomized controlled trial of fresh frozen plasma for coagulopathy in Russell's viper (Daboia russelii) envenoming. J Thromb Haemost. 2017;15:645-654. 